\title{
Mode I Stress Intensity Factor and T-Stress Solutions for Centre Cracked Orthotropic Plates
}

\author{
M. Lallam ${ }^{1,2}$, S. Mamouri ${ }^{1}$ and A. Djebli ${ }^{*}$ \\ ${ }^{1}$ University of Tahri Mohamed, Bechar Algeria \\ ${ }^{2}$ Laboratory of Sciences and Water Technical, University of Mustapha Stambouli, \\ Mascara 29000, Algeria \\ ${ }^{3}$ Laboratory of Quantum Physics of Matter and Mathematical Modeling (LPQ3M), \\ University of Mustapha Stambouli, Mascara 29000, Algeria \\ *Email: djebliabdelkader@univ-mascara.dz \\ Phone: +213552460623
}

\begin{abstract}
The main objective of this paper is the formulation of analytical expressions for the direct calculation of fracture parameters for the case of an orthotropic material with elastic behaviour. Numerical simulation by finite element method is performed to evaluate the singular and non-singular terms of William's series. Based on the obtained results, a fitting procedure is performed to propose an analytical formulation involving the geometric parameters of the plate and the crack in the approximate estimation of these parameters. The importance of the proposed analytical expressions is that they do not require a complex and time-consuming numerical analysis for the computation of the stress intensity factors and T-stresses for such an orthotropic cracked panel. A comparative study between the results obtained by the proposed equations and those obtained by finite element procedure has shown a good correlation.
\end{abstract}

Keywords: Orthotropic materials; stress intensity factor, T-stress, FEM; centre cracked plate.

\section{INTRODUCTION}

Orthotropic materials are increasingly used in different fields of engineering. These materials are often subjected to cyclic loadings that cause damage. This is manifested by the nucleation, then the appearance of propagation of cracks lead to the complete rupture of the structure.

At the beginning of the 20th century, Griffith's energetic analysis of cracks is considered as a basis for the mechanics of fracture [1,2]. This latter proposed a failure criterion to compensate for Inglis infinite stress prediction while making direct use of his linear elastic solution [3]. More than two decades later, the mechanic of linear elastic fracture was introduced by Irwin establishing the theory of stress intensity factor (SIF) [4]. Later in 1948, motivated by the insufficiency of the linear fracture theory, Rice defined the J-Integrale independent of the integration path to solving two-dimensional cracking problems in non-linear elastic materials [5,6]. It is well established that $\mathbf{J}$ is equivalent to the rate of energy restitution defined by Griffith. Thus, J-integral can be used for deduction of SIF [7].

In addition to the SIF, the elastic T-stress provides another parameter to identify the severity of stress and displacement fields near a crack tip [8-10]. In this context, 
Cotterell worked on the singular term T-stress to predict crack growth paths under Mode I condition [11]. In fact, Cotterell and Rice concluded in [12], that for $T<0$ the crack path is always stable, whereas for $T>0$ the propagation becomes unstable. Similar results had been obtained previously in [13, 14], although experimental tests showed the presence of a positive threshold $\mathrm{T}_{\mathrm{th}}>0$ above which instability of crack propagation occurs $[15,16]$. In the same context, the role of T-stress in brittle fracture for linear elastic materials under mixed-mode loading has aroused an extensive works [17-19], where, Smith et al. had shown that brittle fracture could be controlled by a combination of singular stresses (characterised by K) or non-singular stress (T-stress) [20-22]. Moreover, the T-stress is stated to influence brittle fracture when the singular stress field is a result of mode II loading [21, 22].

Similarly to isotropic materials, linear elastic fracture mechanics concepts [9] (LEFM) are used in fracture analysis of orthotropic materials [23-25]. However, unlike isotropic materials where a crack grows perpendicularly to the direction of maximum tension [26], the direction of crack growth in orthotropic materials is governed by the material strength and the stress state [27, 28]. Nevertheless, the SIF and the T-stresses as parameters independent of the crack growth direction and governing the crack stability, respectively, find practical significance in the fracture analysis of such materials [29].

In this paper, a fitting procedure was performed to develop an analytical formulation giving stress intensity factor and different non-singular terms, namely $\mathrm{T}_{11}$, $\mathrm{T}_{13}$ and $\mathrm{T}_{33}$ characterising a failure parameters in linear elastic fracture mechanic. $\mathrm{A}$ numerical analysis is used to evaluate stress intensity factor and T-stress along the crack front in elastic orthotropic panel [8].

\section{GEOMETRICAL MODEL AND MATERIAL PROPERTIES}

The present work is based on the Chung-Yi model [8], respecting all the boundary conditions. This allowed us to validate the results and then address our main objective, which is the elaboration of analytical expressions for a direct calculation of the fracture parameters of a central fissure orthotropic plate. Figure 1 shows the entire plate. It has a total length of $2 \mathrm{l}=2.032 \mathrm{~m}$, a total width of $2 \mathrm{w}=1.016 \mathrm{~m}$, and a total thickness of $2 \mathrm{t}$ $=0.0084 \mathrm{~m}$. The origin of the global Cartesian coordinate system is located at the centre of the plate as it was modelled by [8].

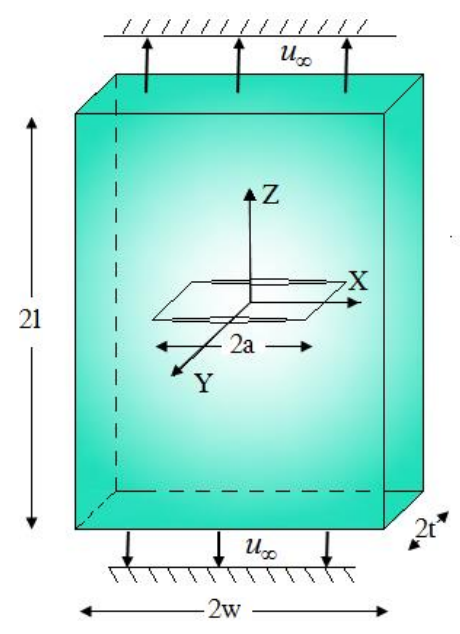

Figure 1. 3D geometric model and loading definition. 
The $\mathrm{X}$-axis is parallel to the crack surface, and the $\mathrm{Y}$-axis is normal to the crack surface. The $\mathrm{Z}$-axis is normal to the $\mathrm{X}-\mathrm{Y}$ plane. A uniform displacement $u_{\infty}$ equivalent to a strain value of $0.1 \%$ is prescribed on the far ends at $Y= \pm 1$ [8]. The studied plate is a composite material known as AS4 used in the aeronautic industry. Table 1 presents the mechanical properties of such material.

Table 1. Mechanical properties of the orthotropic plate [8].

\begin{tabular}{ccccccccc}
\hline $\begin{array}{c}\mathrm{E}_{1} \\
(\mathrm{GPa})\end{array}$ & $\begin{array}{c}\mathrm{E}_{2} \\
(\mathrm{GPa})\end{array}$ & $\begin{array}{c}\mathrm{E}_{3} \\
(\mathrm{GPa})\end{array}$ & $\begin{array}{c}\mathrm{G}_{23} \\
(\mathrm{GPa})\end{array}$ & $\begin{array}{c}\mathrm{G}_{13} \\
(\mathrm{GPa})\end{array}$ & $\begin{array}{c}\mathrm{G}_{12} \\
(\mathrm{GPa})\end{array}$ & $v_{23}$ & $v_{13}$ & $v_{12}$ \\
\hline 35.591 & 81.172 & 10.549 & 4.413 & 3.930 & 17.092 & 0.22 & 0.29 & 0.18 \\
\hline
\end{tabular}

\section{FINITE ELEMENTS MODEL}

Symmetrical boundary conditions are imposed in the $\mathrm{XY}, \mathrm{YZ}$ and $\mathrm{ZX}$ planes as illustrated by Figure 2 . The origin of the local coordinate system $\mathrm{x}_{1} \mathrm{X}_{2} \mathrm{X}_{3}$ is defined on the crack tip. The $\mathrm{x}_{1}$-axis is parallel to the crack surface and collinear with the global $\mathrm{X}$-axis. The $\mathrm{x}_{2}-$ axis is normal to the crack surface, and the $\mathrm{x}_{3}$-axis lies on the crack front and is parallel to global Z-axis (Figure 2). A commercial finite element code ANSYS-12.1 was used for the simulation purpose. Readers can see [8], for a more detailed explanation of the finite element model. Figure 3 shows the generated mesh around the crack domain. As indicated, mesh refinement is used near the crack front, where quadratic wedge elements are surrounding the crack tip. A quadratic brick element was used far away from the crack region as shown in Figure 3(a) and 3(b).

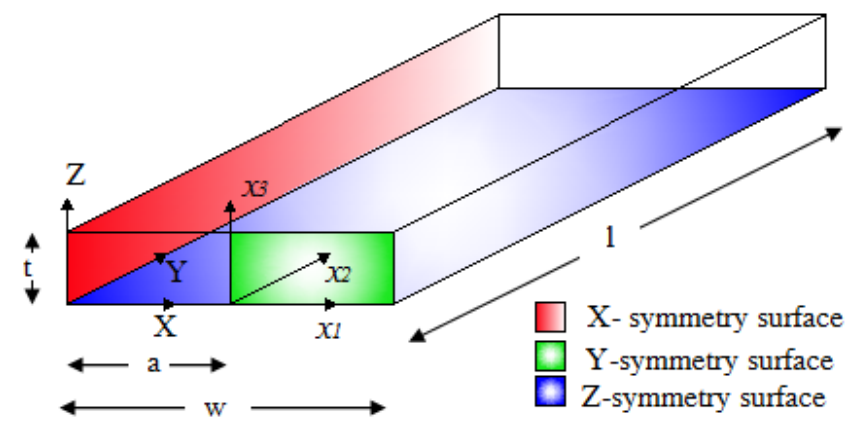

Figure 2. The model symmetry and the local coordinate system definition.

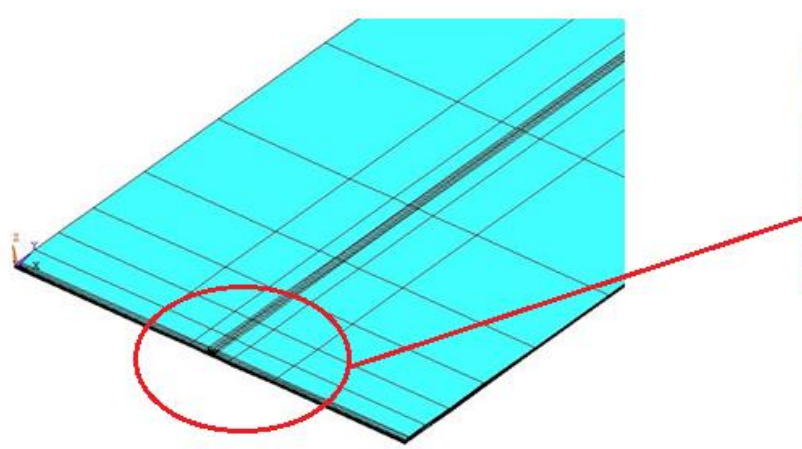

(a)

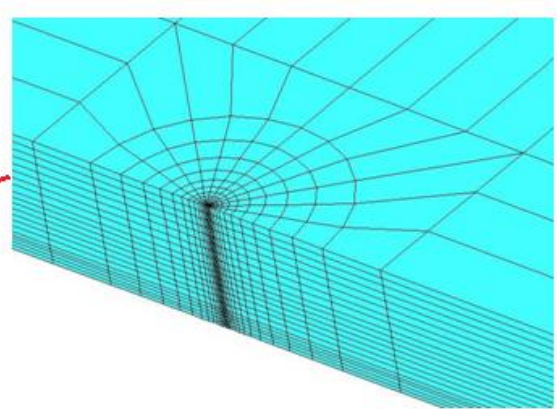

(b)

Figure 3. (a) Complete FE model and; (b) mesh refinement near the crack front region. 
As modelled in [8], the element radial size $\mathrm{e}_{0}$ is kept as $\mathrm{e}_{0} \leq 0.01 \times 1_{\mathrm{c}}$ where, $1_{\mathrm{c}}$ is defined as $1_{c}=\min [a, w-a, t]$, i.e., $e_{0} \leq 0.01 \times 1_{c}$; shown in Figure 4(b). The crack front region is divided to 12 parts, each one contains 12 elements. The width of the element increases as one move away from the crack line. The thickness is divided into 20 layers that gradually decrease in size.

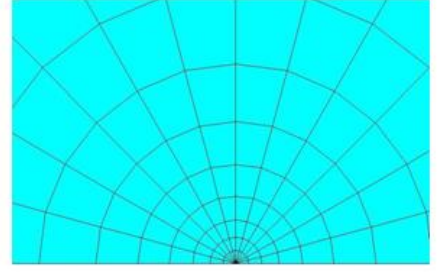

(a)

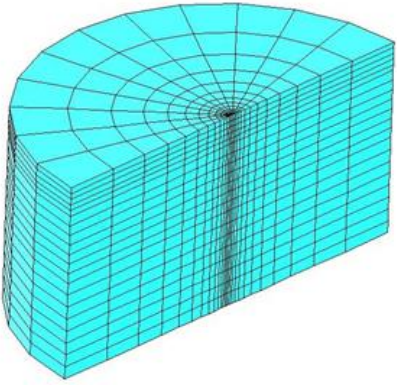

(b)

Figure 4. The mesh around the crack front (a) as viewed in the plane and; (b) along with the thickness.

\section{RESULTS AND DISCUSSION}

\section{Model Validation}

The numerical results obtained in this work are in excellent agreement with those obtained by Chung-Yi $\mathrm{Li}$ in [8]. This allows us to proceed with the analysis and validation of the studied model. In addition, for consolidation of this analysis, the present results are also compared to those published by Yuan and Yang [31]. These researchers used methods based on Betti's reciprocal theorem and the equivalent domain integral (EDI) to extract SIF and T-stress for centre-cracked tension (CCT) specimens of stitched warp-knit fabric composites [31, 32]. Present results are in accordance with those given by Yuan and Yang. The largest deviations are $2.16 \%$ for stress intensity factor $\mathrm{K}_{\mathrm{I}}$ and $2.41 \%$ for $\mathrm{T}_{11}$ stress (Table 2).

Table 2. Comparison of fracture parameters for CCT specimens.

\begin{tabular}{lcccccccc}
\hline$a / w$ & $\begin{array}{c}\text { Thickness } \\
(\mathrm{mm})\end{array}$ & $\begin{array}{c}\text { End } \\
\text { Disp } \\
(\mathrm{mm})\end{array}$ & $\begin{array}{c}\mathrm{K}_{\mathrm{I}}[31] \\
(\mathrm{MPa} \\
\left.\mathrm{m}^{0.5}\right)\end{array}$ & $\begin{array}{c}\text { Actual } \\
\mathrm{K}_{\mathrm{I}} \\
(\mathrm{MPa} \\
\left.\mathrm{m}^{0.5}\right)\end{array}$ & $\begin{array}{c}\text { Error } \\
(\%)\end{array}$ & $\begin{array}{c}\mathrm{T}[31] \\
(\mathrm{MPa})\end{array}$ & $\begin{array}{c}\text { Actual } \\
\mathrm{T}(\mathrm{MPa})\end{array}$ & $\begin{array}{c}\text { Error } \\
(\%)\end{array}$ \\
\hline 0.26 & 8.712 & 0.594 & 60.766 & 60.645 & 0.20 & -308.89 & -308.04 & 0.28 \\
0.34 & 8.788 & 0.569 & 65.711 & 66.384 & 1.02 & -295.10 & -298.18 & 1.04 \\
0.25 & 8.280 & 0.869 & 61.865 & 62.037 & 0.28 & -226.15 & -228.18 & 0.90 \\
0.34 & 8.255 & 0.848 & 69.007 & 70.497 & 2.16 & -219.25 & -224.53 & 2.41 \\
\hline
\end{tabular}

Thus, as indicated by the relative errors, acceptable numerical results are obtained by the model. 


\section{Finite Element Results}

The interaction integral and EDI were implemented into a Fortran 90 computer program. The ECAPE2 program (Fortran 90) was adapted to determine the SIF and T-stress fields. ECAPE2 uses six data files generated by the Ansys program in Batch mode. These data files contain stresses, deformations, displacements, node coordinates, and mechanical properties. The normalised SIF has the form $\overline{K_{I}}=K_{I} /\left(\sigma_{\infty} \sqrt{\pi a}\right)$, while the normalised terms $T$ are defined as $\overline{T_{11}}=T_{11} / \sigma_{\infty}, \overline{T_{13}}=T_{13} / \sigma_{\infty}$ and $\overline{T_{33}}=T_{33} / \sigma_{\infty}$. Where, $\sigma_{\infty}$ is the stress equivalent to the imposed displacement $u_{\infty}$. For this case, $\sigma_{\infty}=F /(w t)$. The position through the plate thickness is also normalised as $\bar{t}=x_{3} / t$ to investigate the KI and the $\mathrm{T}$-stresses over the half thickness of the panel. These parameters are first calculated from each of the three adjacent rows of elements surrounding the crack front (Rings \#2, \#3, and \#4 as shown in figure 4.a) by the equivalent domain integral and interaction integral. Then an average value is calculated over three domains.

Figure 5 presents the normalised SIF curves over half of the thickness for different crack aspect ratios. One can note the symmetry in the distribution of the SIF concerning $x_{3}=0$. It can be mentioned that $\bar{K}_{I}$ is relatively stable through the thickness; an exception is noted in the region near the free surface where the latter decreases slightly. This is due to the free surface singularity. The same trend is observed for all analysed crack lengths (Figure 6). The normalised SIF $\bar{K}_{I}$ increases from 1.00 to 2.54 as the $a / w$ ratio increases as shown by figure 6 . The superposition of the curve of different thickness indicates that $\bar{K}_{I}$ is insensitive to the variation of the plate thickness.

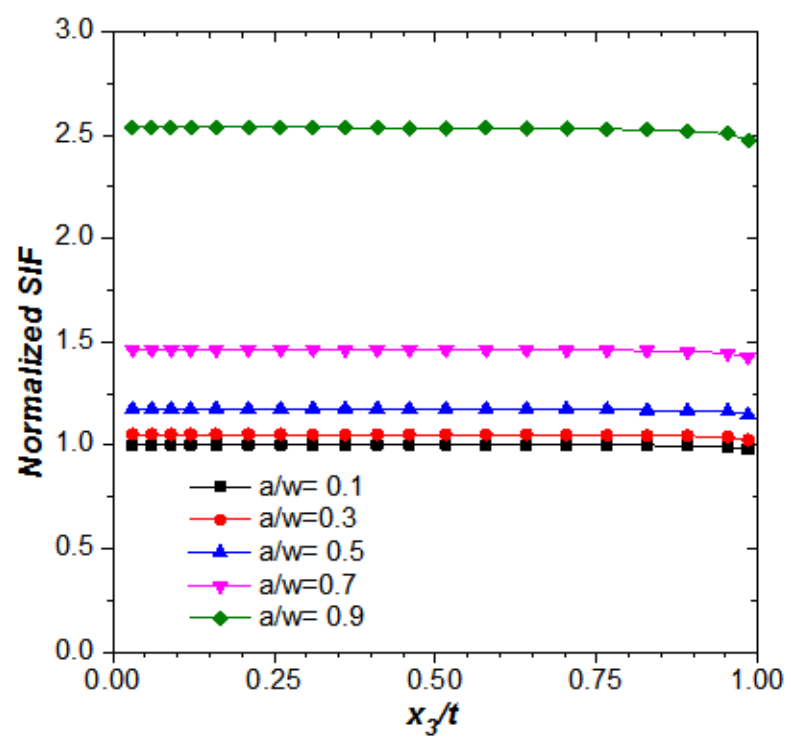

Figure 5. Distribution of the normalised SIF along the crack front for various a/w ratios (case of $\mathrm{t} / \mathrm{w}=0.00825$ ). 


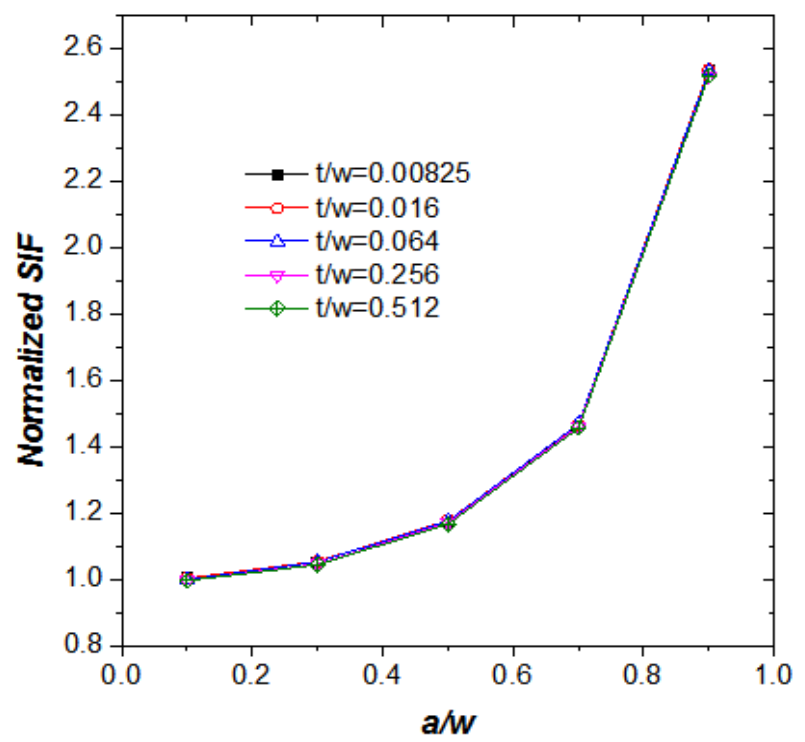

Figure 6. Normalised SIF versus normalised crack lengths at the crack centre for different thicknesses.

In the following, the results relating to the non-singular terms of the William series are presented. For the thinner plate $(t / w=0.00825)$, figure 7 indicates that the distribution of the $\bar{T}_{11}$ over half of the thickness for different crack aspect ratios is symmetric with respect to $x_{3}=0$. Relative monotonous distribution of $\bar{T}_{11}$ is noted over a half of the thickness. An exception is noted in the region near the free surface $(\bar{t} \geq 0.85)$. This is valid for all plate widths (Figure 7).

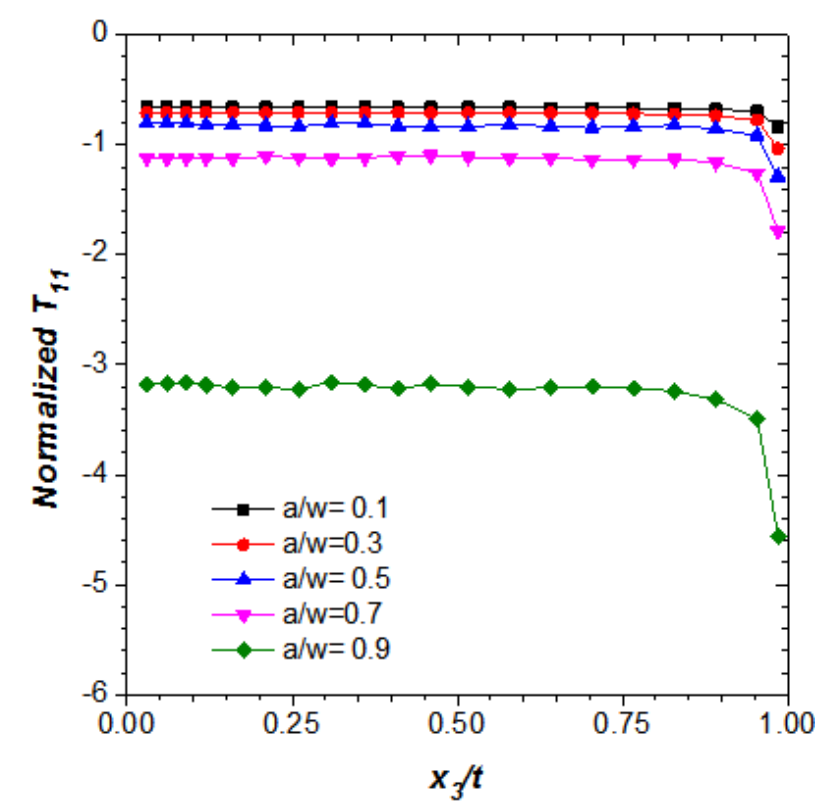

Figure 7. Normalised $\mathrm{T}_{11}$ stresses versus the normalised thickness for different lengths (case of $\mathrm{t} / \mathrm{w}=0.00825$ ).

Figure 8 indicates that the value of $\bar{T}_{11}$ at the centre of the thickness decreases gradually from -0.66 to -3.22 as the $\mathrm{a} / \mathrm{w}$ ratio increases from 0.1 to 0.9 . Identical trends 
are noted for all plate thicknesses indicating the non-dependency of $\bar{T}_{11}$ the term of the plate thickness.

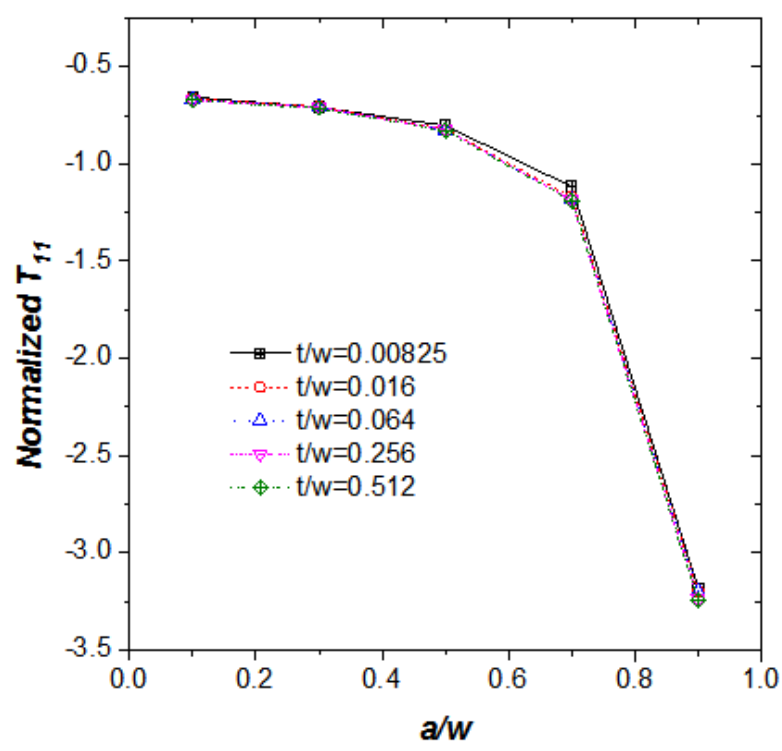

Figure 8. Normalised $\mathrm{T}_{11}$ stresses at the centre of crack front versus the normalised crack length for different thicknesses.

Figure 9 summarises the distribution of the normalised $\mathrm{T}_{13}$ stresses over the half crack front thickness for the case of the thinner plate $(\mathrm{t} / \mathrm{w}=0.00825)$ for different $\mathrm{a} / \mathrm{w}$ ratios. Unlike $\bar{T}_{11}, \bar{T}_{13}$ decreases along the crack front thickness. Note that the trend is antisymmetric with respect to $\mathrm{x}_{3}=0$ (front centre). Instead, the magnitude of the normalised $\mathrm{T}_{13}$ stresses decreases gradually from zero at the centre of thickness to a much smaller value near the free surface. This latter back to zero, to satisfy the free surface condition.

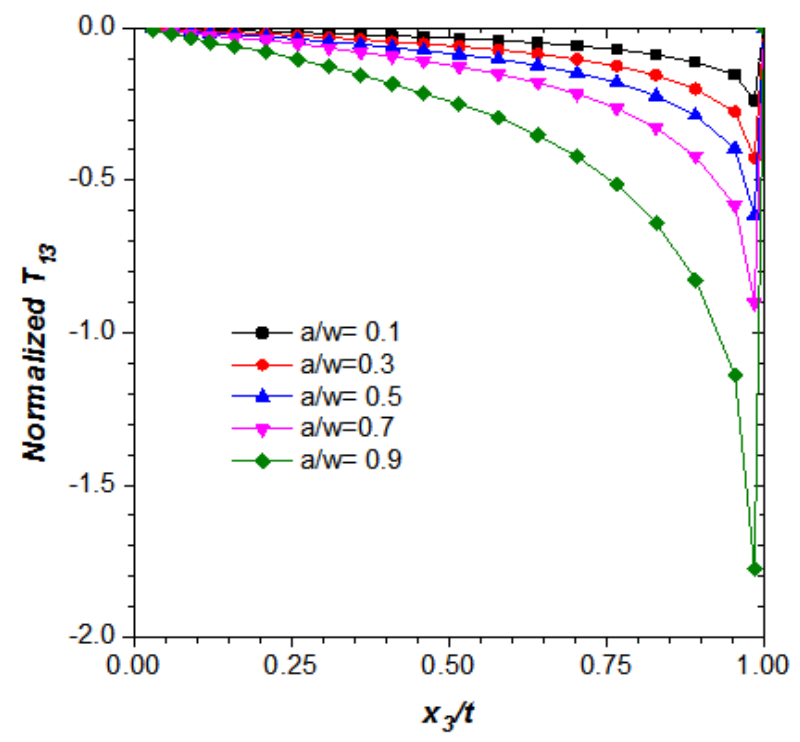

Figure 9. Normalised $\mathrm{T}_{13}$ stresses versus the normalised thickness for different lengths (case of $\mathrm{t} / \mathrm{w}=0.00825$ ). 
Figure 10 presents the values of $\bar{T}_{13}$ at the crack front centre versus the crack length ratios for different thickness to width ratios. It can be mentioned that the $T_{13}$ absolute values increase gradually with respect to a/w ratio. Furthermore, it is indicated that $\mathrm{T}_{13}$ is sensitive to the change in thickness of the plate.

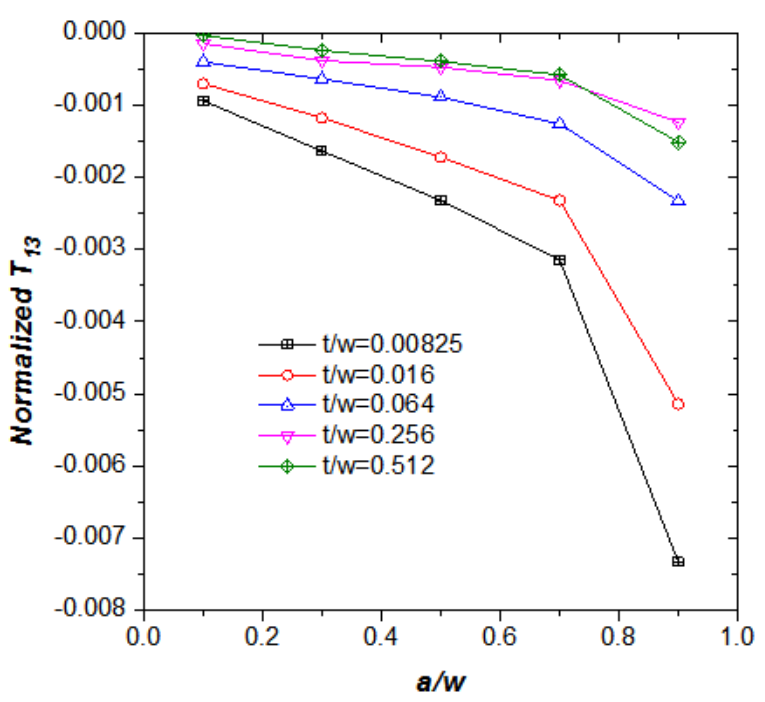

Figure 10. Normalised $T_{13}$ stresses at the centre of crack front versus the normalised crack length for different thicknesses.

Figure 11 resumes the obtained results of the third normalised term $T_{33}$. It can be seen that the trend of $\bar{T}_{33}$ stress is symmetrical with respect to $x_{3}=0$ and it is almost constant when $x_{3} / t<0.40$, but decreases behind this position because of boundary effects.

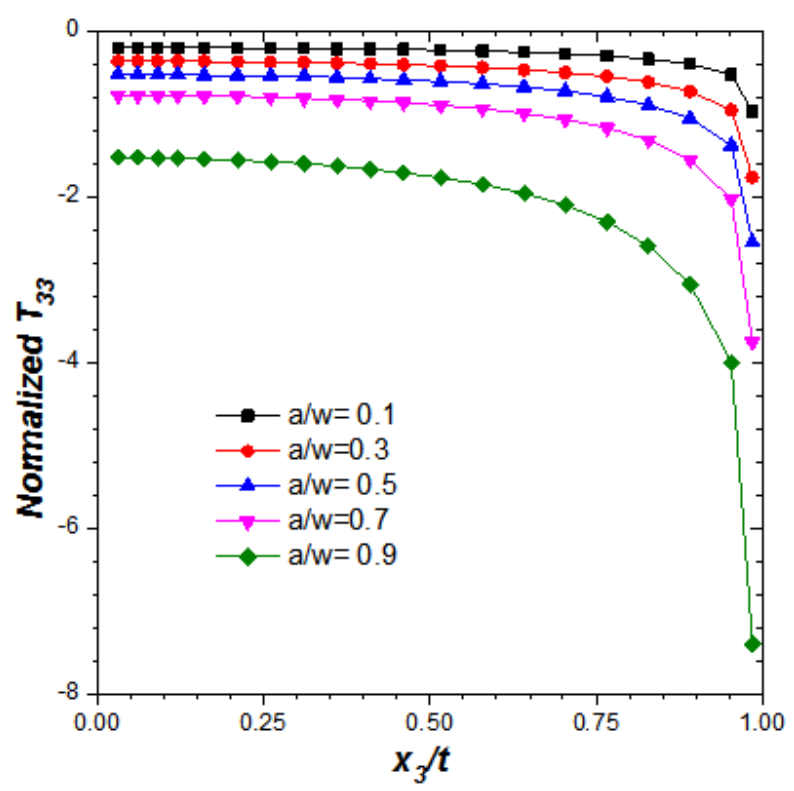

Figure 11. Distribution of the normalised $\mathrm{T}_{33}$ stresses through half of the crack front for various a/w ratios $(\mathrm{t} / \mathrm{w}=0.00825)$. 
Figure 12 presents the normalised $T_{33}$ at the middle position of the crack front as a function of the crack lengths with respect to different plate thickness.

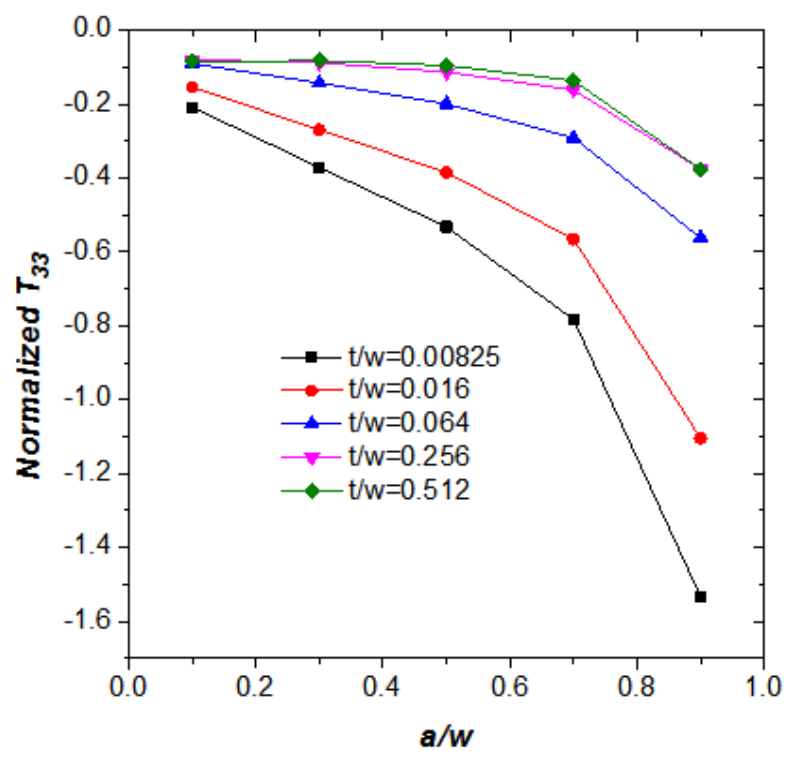

Figure 12. Normalised $\mathrm{T}_{33}$ stresses $\left(\mathrm{x}_{3} / \mathrm{t}=0\right)$ for different thicknesses.

One can see that $T_{33}$-stress increases in absolute value as the crack length increases as well. Figure 12 also indicates that $\bar{T}_{33}$ is dependent on the plate thickness. This dependency becomes non-significant for large thicknesses. At this stage, it is possible to fit the various curves presented above. The goal is to formulate analytical expressions, including the geometric parameters of crack and plate as variables. These combine different factors of rupture such as SIF and T stresses with the $a / w$ and $t / w$.

\section{ANALYTICAL FORMULATION}

Based on the numerical results of the different simulation, analytical expressions have been developed for the convenience of engineering applications. The choice of analytical functions is based on curve fitting trends. A more detailed discussion about the fitting method can be found in $[33,34]$.

The range of applicability of the formulated expressions is $0.1 \leq \mathrm{a} / \mathrm{w} \leq 0.9$ and $0.00825 \leq \mathrm{t} / \mathrm{w} \leq 0.512$. As imposed by the trends of the presented curves in Figure 9 , The normalised stress intensity factor $\overline{K_{I}}$ solutions at $\mathrm{x}_{3} / \mathrm{t}=0$ (mid-plan) can be fitted with polynomial equations which are given by cubic form as follows:

$\overline{\mathrm{K}_{\mathrm{I}}}=\mathrm{A}_{0}+\mathrm{A}_{1}(\mathrm{a} / \mathrm{w})+\mathrm{A}_{2}(\mathrm{a} / \mathrm{w})^{2}+\mathrm{A}_{3}(\mathrm{a} / \mathrm{w})^{3}$

where $A_{i}$ is polynomial factors. These factors are obtained by closely adjusting the curves presented in Figure 9. The coefficients $A_{i}$ vary slightly in relation to the $t / w$ ratios (Table3). Thus, by grouping the different ratio of thickness $t / w$ in curves of $A_{i}$ as a function and making the adjustment, the following expression was obtained. 


$$
\begin{aligned}
& \overline{K_{1}}=\left[0.8235\left(\frac{t}{w}\right)^{-0.0007684}\right]+\left[2.26\left(\frac{t}{w}\right)^{-0.006953}\right] \cdot\left(\frac{a}{w}\right) \\
& -\left[6.926\left(\frac{t}{w}\right)^{-0.006285}\right]\left(\frac{a}{w}\right)^{2}+\left[7.217\left(\frac{t}{w}\right)^{-0.004826}\right]\left(\frac{a}{w}\right)^{3}
\end{aligned}
$$

Table 3. Parameters of polynomial equation fitted for normalised stress intensity factors.

\begin{tabular}{lllll}
\hline \multicolumn{1}{c}{$\mathrm{t} / \mathrm{w}$} & $\mathrm{A}_{0}$ & $\mathrm{~A}_{1}$ & $\mathrm{~A}_{2}$ & $\mathrm{~A}_{3}$ \\
\hline 0.00825 & 0.82522 & 2.3449 & -7.1736 & 7.4135 \\
\hline 0.016 & 0.82859 & 2.3138 & -7.0849 & 7.3505 \\
\hline 0.064 & 0.82377 & 2.3121 & -7.032 & 7.2936 \\
\hline 0.256 & 0.82433 & 2.2693 & -6.9364 & 7.2213 \\
\hline 0.512 & 0.8229 & 2.2788 & -7.0081 & 7.2888 \\
\hline
\end{tabular}

In the same way as for $\overline{K_{I}}$, the normalised T-stresses solutions at $x_{3} / t=0$ (mid-plan) can be fitted with polynomial equations and written as:

$\overline{T_{11}}=B_{0}+B_{1}(a / w)+B_{2}(a / w)^{2}+B_{3}(a / w)^{3}$

$\overline{T_{13}}=C_{0}+C_{1}(a / w)+C_{2}(a / w)^{2}+C_{3}(a / w)^{3}$

$\overline{T_{33}}=D_{0}+D_{1}(a / w)+D_{2}(a / w)^{2}+D_{3}(a / w)^{3}$

Where, $B_{i}, C_{i}$ and $D_{i}$ are polynomial factors which are given in Tables 4, 5 and 6, respectively.

Table 4. Parameters of polynomial equations fitted for normalised $\mathrm{T}_{11}$-stresses.

\begin{tabular}{lllll}
\hline $\mathrm{t} / \mathrm{w}$ & $\mathrm{B}_{0}$ & $\mathrm{~B}_{1}$ & $\mathrm{~B}_{2}$ & $\mathrm{~B}_{3}$ \\
\hline 0.00825 & -0.20699 & -6.0497 & 19.064 & -17.768 \\
\hline 0.016 & -0.25206 & -5.5348 & 17.594 & -16.73 \\
\hline 0.064 & -0.26848 & -5.3722 & 17.164 & -16.434 \\
\hline 0.256 & -0.26506 & -5.4926 & 17.591 & -16.814 \\
\hline 0.512 & -0.26032 & -5.5503 & 17.712 & -16.898 \\
\hline
\end{tabular}

Table 5. Parameters of polynomial equations fitted for normalised $\mathrm{T}_{13}$-stresses.

\begin{tabular}{lllll}
\hline $\mathrm{t} / \mathrm{w}$ & $\mathrm{C}_{0}$ & $\mathrm{C}_{1}$ & \multicolumn{1}{c}{$\mathrm{C}_{2}$} & $\mathrm{C}_{3}$ \\
\hline 0.00825 & 0.00033938 & -0.015998 & 0.03997 & -0.03512 \\
\hline 0.016 & 0.00012799 & -0.010274 & 0.025105 & -0.022396 \\
\hline 0.064 & 0.0001231 & -0.0033759 & 0.007383 & -0.0070505 \\
\hline 0.256 & 0.00012157 & -0.0033238 & 0.0071333 & -0.0056852 \\
\hline 0.512 & 0.00029119 & -0.0040754 & 0.0097606 & -0.0082748 \\
\hline
\end{tabular}


Table 6. Parameters of polynomial equations fitted for normalised $\mathrm{T}_{33}$-stresses

\begin{tabular}{lllll}
\hline \multicolumn{1}{c}{$\mathrm{t} / \mathrm{w}$} & \multicolumn{1}{c}{$\mathrm{D}_{0}$} & \multicolumn{1}{c}{$\mathrm{D}_{1}$} & \multicolumn{1}{c}{$\mathrm{D}_{2}$} & \multicolumn{1}{c}{$\mathrm{D}_{3}$} \\
\hline 0.00825 & -0.0040984 & -2.4953 & 5.6168 & -5.2521 \\
\hline 0.016 & -0.0093321 & -1.7621 & 3.9716 & -3.7357 \\
\hline 0.064 & -0.022163 & -0.82278 & 1.8909 & -1.8231 \\
\hline 0.256 & -0.40026 & -0.50691 & 1.55 & -1.5535 \\
\hline 0.512 & -0.041195 & -0.57417 & 1.9442 & -1.9061 \\
\hline
\end{tabular}

In the same way, as for normalised SIF, the analytic expressions of normalised $T_{11}, T_{13}$ and $T_{33}$ are given by writing the different factors $B_{i}, C_{i}$ and $D_{i}$ as adjusted by a power law. As a result, expressions of normalised $T_{11}$, normalised $T_{13}$ and $T_{33}$ are obtained as follows:

$$
\begin{aligned}
& \overline{T_{11}}=-0.2791\left(\frac{t}{w}\right)^{0.04044}-5.358\left(\frac{t}{w}\right)^{-0.01596} \cdot\left(\frac{a}{w}\right) \\
& +17.21\left(\frac{t}{w}\right)^{-0.01283} \cdot\left(\frac{a}{w}\right)^{2}-16.56\left(\frac{t}{w}\right)^{-0.008073}\left(\frac{a}{w}\right)^{3} \\
& \overline{T_{13}}=1.528 E-05\left(\frac{t}{w}\right)^{-0.6027}-0.001264\left(\frac{t}{w}\right)^{-0.52} \cdot\left(\frac{a}{w}\right)^{-0.5771}\left(\frac{a}{w}\right)^{3} \\
& +0.002336\left(\frac{t}{w}\right)^{-0.5852} \cdot\left(\frac{a}{w}\right)^{2}-0.002139\left(\frac{t}{w}\right)^{-0.5} \\
& \overline{T_{33}}=-0.05928\left(\frac{t}{w}\right)^{0.4019}-0.2718\left(\frac{t}{w}\right)^{-0.4577} \cdot\left(\frac{a}{w}\right)^{-0.3444}\left(\frac{a}{w}\right)^{3} \\
& +0.9263\left(\frac{t}{w}\right)^{-0.3646} \cdot\left(\frac{a}{w}\right)^{2}-0.95\left(\frac{t}{w}\right)^{3}
\end{aligned}
$$

\section{VALIDATION OF THE PROPOSED ANALYTICAL EXPRESSIONS}

To consolidate the validation of the proposed expressions in this work, it is preceded to complementary modelling of the orthotropic fissured plate. Different parameters were used compared to the first analysis. Thus, comparison of the FEM results to those given by the proposed expressions was made. Figures 13(a) and 13(b) shows an example of the normalised $\mathrm{K}_{\mathrm{I}}$ calculated by FEM compared to that calculated analytically using equation 2.

The proposed solution fits well with the values obtained numerically. Typical results of T-stresses from finite element analysis and analytical equations for $\mathrm{t} / \mathrm{w}=0.00825$ and 0.016 are shown in Figure 14. All the results of the non-singular terms (T-stresses) calculated numerically by FEM are in good correlation with results obtained by the proposed analytical solutions given by Eq. (6) to (8). 


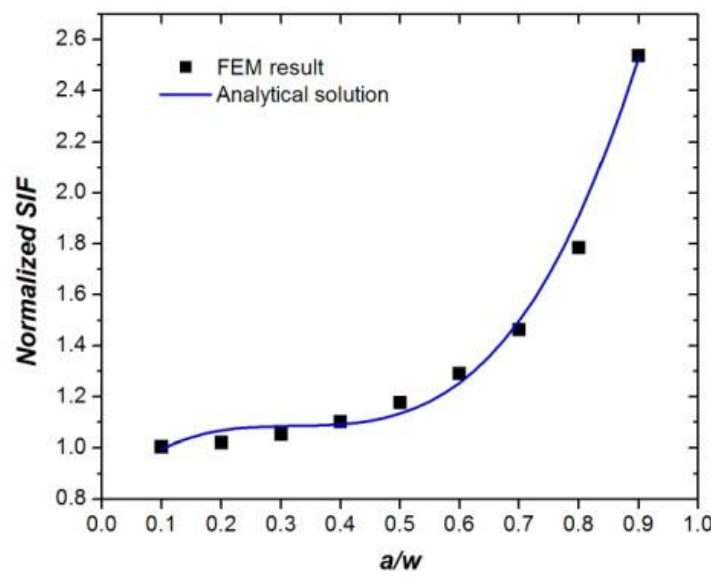

(a) $t / w=0.00825$

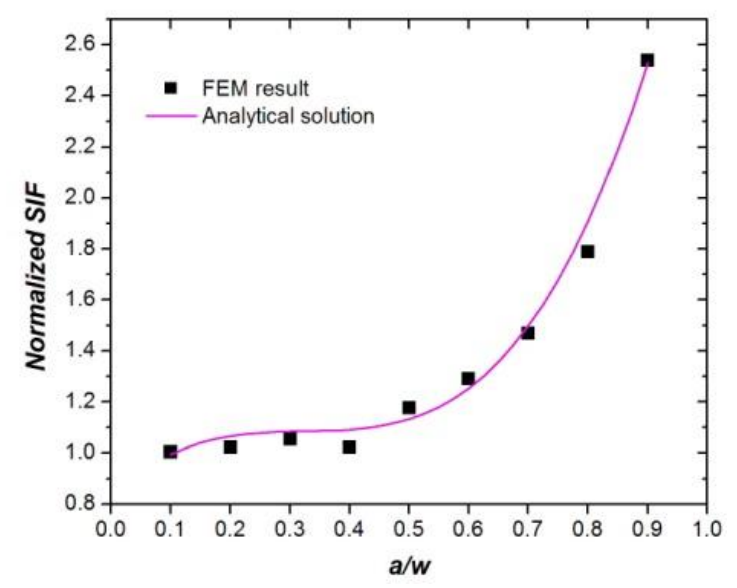

(b) $\mathrm{t} / \mathrm{w}=0.016$

Figure 13. Comparison of FEM results and the proposed analytical expression for normalised SIF.

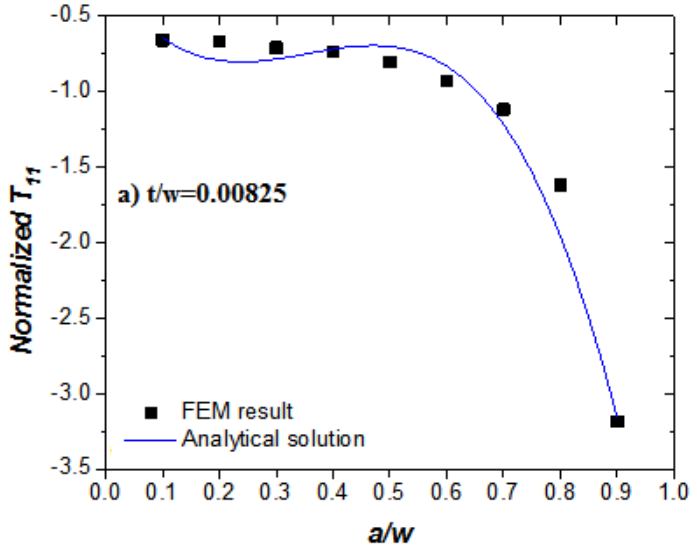

(a) normalised $\mathrm{T}_{11}$ for $\mathrm{t} / \mathrm{w}=0.00825$

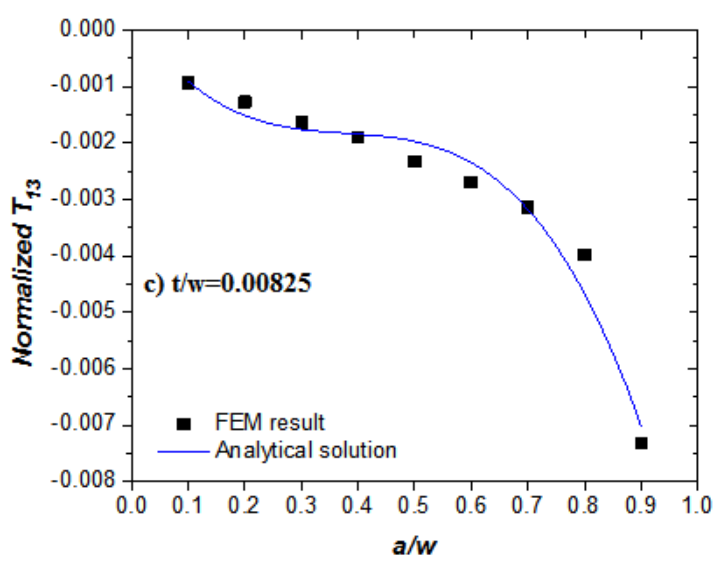

(c) normalised $\mathrm{T}_{13}$ for $\mathrm{t} / \mathrm{w}=0.00825$

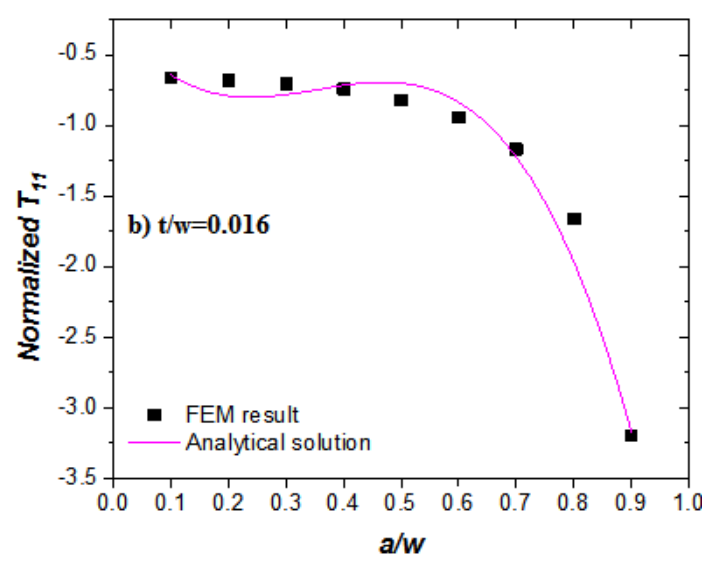

(b) normalised $\mathrm{T}_{11}$ for $\mathrm{t} / \mathrm{w}=0.016$

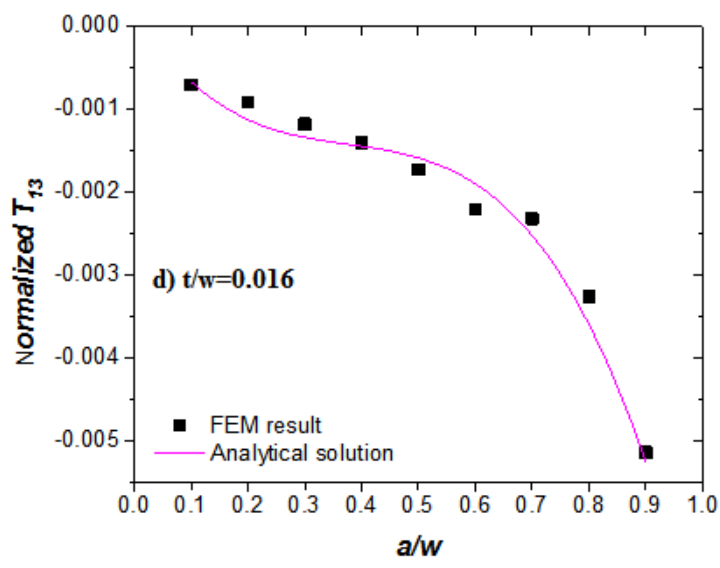

(d) normalised $\mathrm{T}_{13}$ for $\mathrm{t} / \mathrm{w}=0.016$ 


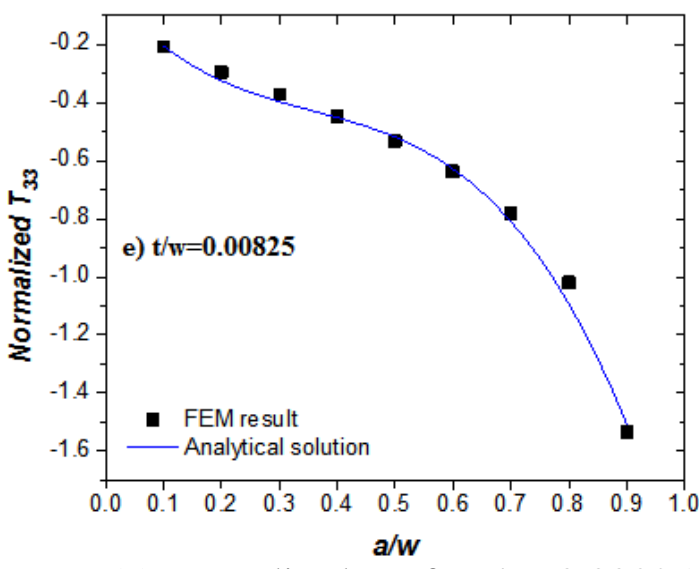

(e) normalised $\mathrm{T}_{33}$ for $\mathrm{t} / \mathrm{w}=0.00825$

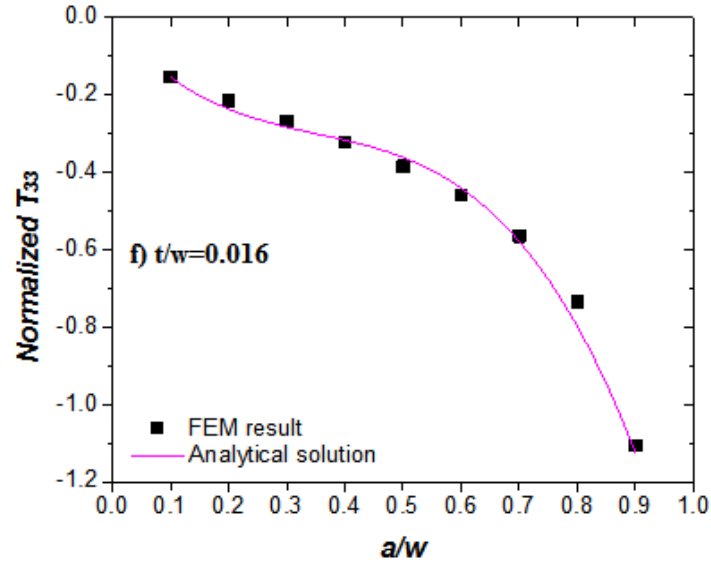

(f) normalised $\mathrm{T}_{33}$ for $\mathrm{t} / \mathrm{w}=0.016$

Figure 14. Comparison of FEM results and the proposed expressions for normalised Tstresses.

\section{CONCLUSION}

A 3D finite element models have been realised to compute the SIF and components of nonsingular terms $\mathrm{T}$-stress for orthotropic centre-cracked plates. A parametric study has been conducted, and analytical formulations giving $\mathrm{K}_{\mathrm{I}}, \mathrm{T}_{11}, \mathrm{~T}_{13}$ and $\mathrm{T}_{33}$ were proposed. The relative crack depth $a / w$ is varied by $0.1,0.3,0.5,0.7$ and 0.9 . And the relative thickness of the specimen $\mathrm{t} / \mathrm{w}$ is chosen as $0.00825,0.016,0.064,0.256$ and 0.512 . The main conclusions are as follows:

i. Stress intensity factor $\left(\mathrm{K}_{\mathrm{I}}\right)$ is independent of the thickness.

ii. The distribution of SIF adopts the same trend regardless of the thickness in the studied range.

iii. The same observations were made for the $\mathrm{T}_{11}$.

iv. The $\mathrm{T}_{13}$ is dependent on the thickness. The latter is antisymmetric.

v. The $T_{33}$ is dependent on the thickness but adopts a trend similar to that of $K_{I}$ and $\mathrm{T}_{11}$. In other words, $\mathrm{T}_{33}$ is distributed similarly for the different thicknesses of the orthotropic plate.

vi. Adequate adjustments can be used to develop simple and easy-to-use expressions for calculating break parameters.

vii. As indicated by the different comparisons, all the results of fracture parameters from analytical expressions are in very good agreement with those performed by the finite element analysis. Thus, for reasons of simplicity, these analytical formulations can be used for the encountered engineering applications dealing with the case of cracked orthotropic structures.

\section{REFERENCES}

[1] Griffith AA. The phenomena of rupture and flow in solids. Philosophical Transaction of the Royal Society of London, Series A 1920; 221: 163-198

[2] Gross D and Seelig T. Fracture mechanics with an introduction to transaction of micromechanics.2nd ed. New York: Springer; 2011.

[3] Irwin GR. Onset of fast crack propagation in high strength steel and aluminum alloys. In: Segamore Research Conference Proceedings, 2, pp.289-305; 1956. 
[4] Rice JR. A path independent integral and the approximate analysis of strain concentration by notches and cracks. Journal of Applied Mechanics 1968; 35: 379- 386.

[5] Parks DM. The virtual crack extension method for nonlinear material behavior. Computer Methods in Applied Mechanics and Engineering 1977; 12: 353-364.

[6] Guz AN, Guz IA, Men'shikov AV, Men'shikov .VA. Three-dimensional problems in the dynamic fracture mechanics of materials with interface cracks (review). International Applied Mechanics 2013;49: 1-61.

[7] Radaj D. Fatigue assessment of welded joints by local approaches. Material Wissenschaft und Werkstofftechnik 2006;37:1050.

[8] Chung-Yi L. Determination of the fracture parameters in a stiffened composite panel. PhD Dissertation. North Carolina State University; Dept. of Mechanical Engineering; Raleigh, NC United States; 2000.

[9] Anderson TL. Fracture mechanics: fundamentals and applications. New York: CRC Press. 1995.

[10] Ayatollahi MR, Razavi. SMJ, Rashidi Moghaddam M, Berto F. Mode I fracture analysis of polymethylmetacrylate using modified energy-based models. Physical Mesomechanics 2015; 18: 326-336.

[11] Cotterell B. Notes on paths and stability of cracks. International Journal of Fracture Mechanics 1966; 2 (3): 526 - 533.

[12] Cotterel B, Rice JR. Slightly curved or kinked cracks. International Journal of Fracture 1980;16: 155-169.

[13] Banichuk NV. Determination of the form of a curvilinear crack by small parameter technique 1970; Izv. AN SSR, MTT (Mechanics of solids) 7: 130137(in Russian).

[14] Gupta M, Alderliesten RC, Benedictus R. A review of T-stress and its effects in fracture mechanics. Engineering Fracture Mechanics 2015; 134: 218-241.

[15] Sumi Y, Nemat-Nasser S, Keer LM. On crack path stability in a finite body Engineering Fracture Mechanics 1985; 22: 759-771.

[16] Chao YJ, Liu S, Broviak BJ. Brittle fracture: Variation of fracture toughness with constraint and crack curving under mode I condition. Experimental Mechanics 2001; 41: 231-241.

[17] Smith DJ, Ayatollahi MR, Pavier MJ. The role of T-stress in brittle fracture for linear elastic materials under mixed-mode loading. Fatigue Fract Engng Mater Struct 2000; 24:137-150.

[18] X Liu Y, Dai Y. Characteristics and effects of T-stresses in central- cracked unstiffened and stiffened plates under mode I loading. Engineering Fracture Mechanics 2017; 181 (1): 393-415.

[19] Naik RA, Crews JH Jr. Determination of stress intensity factors for interface cracks under mixed-mode loading. NASA Technical Reports Server 1992.

[20] Liu S, Chao YJ. Variation of fracture toughness with constraint. International Journal of Fracture 2003;124:113-117.

[21] Hongyan L. Wing-crack initiation angle: A new maximum tangential stress criterion by considering $\mathrm{T}$-stress. Engineering Fracture Mechanics 2018;199:380- 391.

[22] Rashidi MR, Ayatollahi MR, Razavi SMJ, Berto F. Mode II brittle fracture assessment using an energy-based criterion. Physical Mesomechanics 2017; 20: $142-148$. 
[23] Chakraborty D, Murthy KSRK, Chakraborty D. Experimental determination of mode I stress intensity factor in orthotropic materials using a single strain gage. Engineering Fracture Mechanics 2017; 173: 130-145.

[24] Bathias C, Esnault R, Pellas J. Application of fracture mechanics to graphite fiber reinforced composites. Composites 1981; 12: 195-200.

[25] Rashetnia R, Mohammadi S. Finite strain fracture analysis using the extended finite element method with new set of enrichment functions. International Journal for Numerical Methods in Engineering 2015; 102: 1316-1351.

[26] da Silva LFM; Campilho RDSG. Advances in numerical modeling of adhesive joints. Computational Mechanics 2012; 1107: 1-93.

[27] Aidy A, Brown MW, Rodopoulos CA. Modelling of crack coalescence in 2024T351 Al alloy friction stir welded joints. International Journal of Fatigue 2008; 30: 2030-2043.

[28] Gustafsson E, Marth S, Karlsson L, Oldenburg M. Strain and stress conditions at crack initiation during shearing of medium- and high-strength steel sheet. International Journal of Mechanical and Materials Engineering 2017; 12.

[29] Aucott L, Huang D, Dong HB, Wen SW, Marsden J, Rack A, Cocks ACF. A three-stage mechanistic model for solidification cracking during welding of steel. Metallurgical and Materials Transactions A 2018; 49(5): 1674-1682.

[30] Natarajan S, Song C, Belouettar S. Numerical evaluation of stress intensity factors and $\mathrm{T}$-stress for interfacial cracks and cracks terminating at the interface without asymptotic enrichment. Computer Methods in Applied Mechanics and Engineering 2014; 279: 86- 112.

[31] Yuan FG, Yang S. Fracture behavior of stitched warp-knit fabric composites. International Journ al of Fracture 2001; 108: 73-94.

[32] Yuan FG. Determination of stress coefficient terms in cracked solids for monoclinic materials with plane symmetry at $x 3=0$. NASA Contractor Report, NASA/CR-1998-208729, 1998.

[33] Djebli A, Bendouba M, Della N, Aid A, Benhamena A. Finite element modeling and analytical solution of a semi-elliptic crack's J-integral. Recueil de mécanique 2017; 2(1): 125-135.

[34] Bendouba M, Djebli A, Aid A, Benseddiq N, Benguediab M. Time-dependent Jintegral solution for semi-elliptical surface crack in HDPE. CMC: Computers, Materials \& Continua 2015; 45(3), 163-186. 